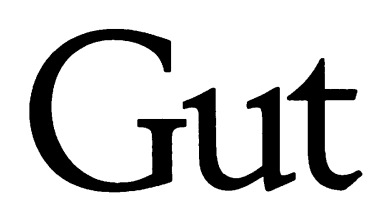

Leading article

\title{
Gastric surfactant and the hydrophobic mucosal barrier
}

The old wives tale of an 'inside lining' protecting the stomach wall against acid retains a certain intuitive appeal, which has found refuge in the concept of a gastric mucosal barrier to the back-diffusion of hydrogen ions. Preference for a physical barrier arose from the many fundamental physiological studies of Horace Davenport and coworkers in the $1950 \mathrm{~s}-1970 \mathrm{~s},{ }^{12}$ and offered many theoretical advantages over alternative mechanisms proposed for mucosal protection. ${ }^{3}$ Davenport envisaged the gastric mucosal barrier as distinct from the mucus layer - or mucus/bicarbonate blanket ${ }^{4}$ - which, arguably, offers inadequate protection because refined mucus is too permeable to hydrogen ions while mucus is absent from the extremely corrosive environment of the oxyntic duct and sparse, if not absent, ${ }^{5}$ from considerable areas of the lumen of the stomach, especially in certain monogastric mammals such as the dog.

\section{Hydrophobicity}

A striking property of the stomach wall is its hydrophobicity as witnessed when the present writer placed a droplet of water on the luminal surface of canine mucosa rinsed free of gastric contents to find that it 'beaded up', as though placed on Polythene, rather than spontaneously wetting the surface as anticipated on a hydrophilic mucoid layer. It was even more interesting to find that this hydrophobicity, as quantified by the contact-angle $(\theta)$ made by the droplet on the surface, was largely eliminated by the major 'barrier breakers' - that is, bile salts, ethanol, and aspirin. ${ }^{6}$ Northfield and his group have subsequently used $\theta$ as a quantifiable clinical index of active gastritis and one still viable even if the barrier breaker is Helicobacter pylori. ${ }^{7}$

\section{Surfactant adsorption}

This raises the question of what substance might be transforming the hydrophilic mucoid layer into a surface so hydrophobic that the contact angle in many normal stomachs can exceed $90^{\circ}$ - that is, approaching that of Polythene $\left(93^{\circ}\right)$ or Teflon $\left(108^{\circ}\right)$. In the physical sciences such transformations are routinely effected by the adsorption (binding) of synthetic surfactants (see Figure (A)) when many of their adsorbed layers are much exploited commercially for the protection that they afford the surface against corrosion. ${ }^{8}$ For instance, the 'underseal' protecting a motorcar against rusting is provided by a hydrophobic monomolecular layer (monolayer) of a synthetic sur- factant, the visible coating being applied simply to protect that monolayer from abrasion by sand and stones.

It was the realisation ${ }^{9}$ that many of the synthetic surfactants used as 'corrosion inhibitors' had similar chemical structures to dipalmitoyl phosphatidylcholine (DPPC) - that is, the surface active component of lung surfactant - which led this writer to perform the hydrophobicity test described above. About that time phospholipid had been discovered in a predominantly saturated form (including DPPC) in gastric juice and in 'light scrapings' from the stomach wall, ${ }^{10}$ later confirming its composition $^{11}$ and surface activity. ${ }^{6}$

\section{Morphology}

If surface active phospholipid (SAPL) provides the outermost layer of the gastric mucosa it is not surprising that electronmicroscopy failed to demonstrate a gastric mucosal barrier when using conventional aldehyde fixatives as these, and glutaraldehyde in particular, destroy hydrophobic surfaces. ${ }^{12}$ Substituting tannic acid, it was possible to demonstrate an oligolamellar layer of SAPL on the luminal surface, displaying its characteristic interlaminar spacing of about $45 \AA^{13}$ while Lichtenberger's group demonstrated SAPL in similar locations using iodoplatinate fixation. ${ }^{14}$ They also demonstrated almost the same hydrophobicity however much they rinsed the mucosal surface, ${ }^{15}$ indicating the ability of the hydrophobic lining to coalesce and reform.

The most exciting finding to this writer was the many ${ }^{10-14}$ layers of SAPL coating the epithelial surface of oxyntic ducts $^{13}$ as these surfaces are mucus free yet exposed to a particularly corrosive environment in which pepsinogen has been secreted from chief cells to mix with $\mathrm{HCl}$ at a $\mathrm{pH}$ of 1 . The source of the SAPL seems to be lamellar bodies found in parietal cells and mucus neck cells ${ }^{13}{ }^{16}$ with some reported in chief cells. ${ }^{16}$ Lamellar bodies are unequivocally the form in which SAPL is produced in the lung. ${ }^{17}$

Surface mucus is interesting because the many classic studies of the Slomianys have established the cytoprotective effect of phospholipid and the reduced permeability to hydrogen ions that it can impart to mucus. ${ }^{18-20}$ Our studies would agree with that finding but, with such a very low solubility of DPPC in the aqueous environment, amounting to a critical micelle concentration of only $5 \times 10^{-10}$ molar, ${ }^{21}$ it is this writer's contention that the SAPL is present largely as the intergranular matrix 
material of unsecreted mucus, ${ }^{22}$ which, in any case, provides the major resistance to hydrogen ions diffusing from the lumen of the stomach to the vital organelles of surface mucus cells. ${ }^{20}$ Just a monolayer of SAPL adsorbed to a filter paper decreases its permeability to hydrogen ions by an order of magnitude. ${ }^{23}$ Thus unsecreted mucus is effectively a number of mini-barriers of SAPL in series, ${ }^{22}$ which explains why the $\mathrm{pH}$ gradient seems to be effectively continuous $^{24}$ and why mucus offers less resistance to acid and becomes less viscous the more it is 'refined', ${ }^{4}$ refinement removing the insoluble intergranular matrix of SAPL.

In interpreting electronmicrographs it is always prudent to be aware of possible artefacts. Although the formation of oligolamellar layers of SAPL is not one of those normally listed, ${ }^{25}$ there must be much SAPL present for these lamellations to form even if they are artefact; although epifluorescense microscopy would tend to confirm their reality. ${ }^{13}$

\section{Helicobacter pylori}

These ultrastructural studies have been extended to the parasites that can survive in the highly corrosive environment of the stomach. Thus it was interesting to find some evidence of oligolamellar SAPL on the cuticle of the Barber's Pole worm, which thrives in the abomasum of Australian sheep, and essentially the same coating on $H$ pylori. ${ }^{26}$ It is similar to SAPL found on the cuticles of many creatures, including the $\operatorname{cockroach}^{27}$ - which is difficult to kill because droplets of any aqueous insecticide simply 'bounce off' those hydrophobic creatures unless a wetting agent is incorporated. Gastric mucus is also a wetting agent ${ }^{28}$ and this could stabilise the surfactant layer on the gastric mucosa by reducing the surface energy of what is otherwise (Figure C) a high energy interface with aqueous gastric contents.

\section{Basic physiology}

Physiologically, a gastric mucosal barrier of SAPL is not only compatible with the many studies of Davenport, ${ }^{2}$ for example, it has the same $\mathrm{pK}$ value (buffering capability) as phosphate and is more permeable to lipids than aqueous solutes, but such layers are also good electrical insulators. ${ }^{29}$ This is exploited in vivo by SAPL in the form of myelin and can explain changes in the electrical characteristics of the gastric mucosa $\mathrm{a}^{30}$ and the desired shift in $\mathrm{pH}$ gradients ${ }^{31}$ induced by fortifying the barrier with exogenous SAPL. Another interesting aspect is the role of prostaglandins where the administration of $\mathrm{PGE}_{2}$ not only protects against ulcers but promotes the secretion of SAPL and enhances hydrophobicity in doing so. ${ }^{32}$

\section{Barrier breakers}

Of more direct clinical relevance, stress ulcers are associated with a change in the lipid profile of the gastric mucosa, ${ }^{33}$ while each of the barrier breakers displays some affinity for SAPL. Bile salts form a chemical complex with SAPL and ethanol is a solvent for SAPL, while nonsteroidal anti-inflammatory drugs (NSAIDs) inhibit the production of prostaglandins controlling SAPL synthesis as reviewed elsewhere. ${ }^{4}$ Hence it is easy to envisage the synergisms that occur between them as they all erode the same barrier, eventually permitting the back diffusion of sufficient acid to produce a gastric ulcer. An interesting exception is $H$ pylori, which might be expected to function as a barrier breaker by secreting phospholipase $A_{2}$, which is found in abundance in these bacteria ${ }^{35}$ and is very effective in digesting SAPL. The aggresive capability of lysates of $H$ pylori on SAPL layers has been demonstrated recently. ${ }^{36}$ Thus $H$ pylori might ingest SAPL, ${ }^{26}$ but would refrain from secreting phospholipase for fear of compromising their own defence against acid as outlined above, possibly explaining why so few gastric ulcers are associated with these bacteria. Another fascinating aspect of $H$ pylori is why these bacteria are not found in the duodenum where they do cause ulcers. ${ }^{37}$ Upon entering the duodenum they would encounter bile which, as a very effective barrier breaker, would remove their protective coating of SAPL, causing them to distintegrate and deposit their 'package' of potent enzymes. ${ }^{26}$ It is also interesting that no synergism between $H$ pylori and other barrier breakers seems to have been reported and this may indicate a compromise between the synergism expected and the capability of other barrier breakers to remove their defence against acid, thus destroying them. This argument is consistent with the reduced prevalence of these bacteria in patients using NSAIDs. ${ }^{38}$

\section{Lubrication}

If the gastric mucosal barrier is provided by surfactant, then the same basic metabolic deficiency that predisposes the subject to gastritis could also compromise the same oligolamellar structure of ubiquitous SAPL elsewhere in the body, ${ }^{39}$ whether its functions are barrier-like or lubrication. Thus it is interesting that patients with peptic ulcer displayed impaired pulmonary function. ${ }^{40}$ SAPL displays excellent high load bearing lubrication and is now one of the leading contenders as the lubricant in the joints ${ }^{41}$ and at other sliding surfaces in vivo, for example, facilitating gastric motility both from within the gastrointestinal tract ${ }^{11}$ and from within the peritoneal cavity. ${ }^{42}$ In animal joints it is interesting that the induction of arthritis sensitises them to peptic ulcer ${ }^{43}$; while NSAIDs have been shown to have an adverse effect upon articular cartilage in animal studies. ${ }^{44}$ If NSAIDs are 'barrier breakers' not only to the gastric mucosal barrier but also to the structure providing lubrication, possibly compromising other desirable physiological functions, ${ }^{41}$ it raises a serious clinical problem concerning their widespread prescription for the relief of pain in the rheumatic diseases. ${ }^{44}$

\section{Exogenous surfactant}

If the gastric mucosal barrier is a physical reality composed of SAPL, then it should be possible to protect against peptic ulcer by administering exogenous SAPL, or promoting its secretion. In the second case $\mathrm{PGE}_{2}$ analogues such as misoprostol are successful as discussed above, while moderate protection has been reported using ambroxol $^{45}$ which, in the lung, at least, is known to promote the secretion of SAPL. 46

Many animal studies have now been reported in which mucosal protection has been derived from exogenous surfactant administered in various forms, including a commercial grade of lecithin ${ }^{47}$ and others ${ }^{48}{ }^{49}$ using a variety of challenges. One of the more interesting avenues is dietary SAPL because this could be useful clinically for preventing ulcers, especially in NSAID patients. Dietary SAPL is available to some degree in milk, which has a modest protection rate, ${ }^{50}$ while claims have been made for plantain bananas boiled and eaten as vegetables in India. ${ }^{51}$ We sought a source of lamellar bodies as SAPL 'packaged' in a much more potentially surface active physical state, and found them in ripe bananas, which were very effective in rats, especially when dispersed in milk or a fat reduced dairy product. ${ }^{52}$ If a little egg yolk is added to boost the SAPL content and the puree spray dried, a powder of all natural ingredients is produced ${ }^{53}$ for 
A B

Cationic corrosion inhibitor Protection by 'phosphating'

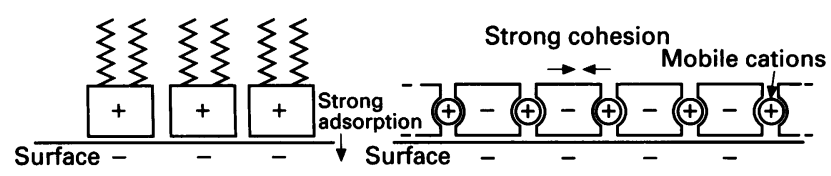

C Gastric surfactant

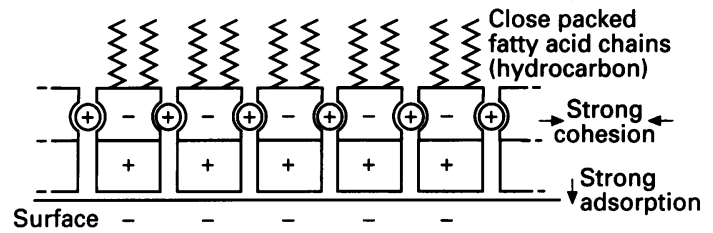

Molecular models for surface protection $(A)$ by adsorption of a cationic surfactant, the most effective industrial corrosion inhibitors having a terminal quaternary ammonium ( $Q A$ ) ion and straight (saturated) alkyl chains, ideally $C_{16}{ }_{16}^{59}$; adsorption is good but cohesion may not be; (B) by the time honoured process of 'phosphating' ${ }^{60}$ in which highly charged mobile cations 'pull' negatively charged phosphate ions into a cohesive barrier - as in 'Pink Primer' - but adhesion to the surface can fail; (C) by the system envisaged in vivo where the Celestial Committee designing the stomach have effectively combined $(A)$ and $(B)$, ensuring cohesion by placing mobile cations between the phosphate groups whose central location does not interfere with strong adsorption of the terminal quarternary ammonium ions of the SAPL molecules enhanced by neutralisation of the phosphates. The cohesive force pulls the straight $C_{16}$ hydrocarbon chains into a close packed hydrocarbon structure resembling a very thin polythene layer - a popular substance for fabricating acid containers and one of comparable hydrophobicity to the stomach. Redrawn from Hills. ${ }^{54}$.

which protection rates have reached $80-90 \%$, leading to clinical trials that are now in progress.

An alternative approach in enhancing a gastric mucosal barrier is to bind the indigenous (or exogenous) SAPL more effectively, improving phosphate to phosphate ionic bonds by interspersing highly charged cations - see Figure (C). Tighter binding of phosphate groups - as in 'phosphating' (Figure (B)) - 'pulls' the outwardly orientated fatty acid chains together and, since these are straight (saturated), they will pack tightly into a very cohesive hydrocarbon barrier to water (Figure (C)) and, hence, to the hydrogen ion. ${ }^{23}{ }^{54}$ In any aqueous environment these are never $\mathrm{H}^{+}$ (a proton) but $\mathrm{H}\left(\mathrm{H}_{2} \mathrm{O}\right)_{3}{ }^{+}{ }^{55}$ This compact barrier structure would be dislocated if the surfactant molecules were to lose one alkyl chain, explaining why lysolecithin is such an effective barrier breaker. ${ }^{19}$ Cohesion imparted by phosphate to phosphate bonding by cations may be one reason why aluminium hydroxide is more effective than other antacids and why sucralfate is effective as the aluminium salt, ${ }^{55} \mathrm{Al}^{3+}$ ions reducing the area per molecule of a monolayer of SAPL by about $30 \%{ }^{57}$ Incidentally, sucralfate is moderately surface active. ${ }^{54}$ The same ionic mechanism could apply to the 'gold plated stomach' ${ }^{58}$ where gold salts administered intravenously or intramuscularly for rheumatoid arthritis have been found to reduce the ulceration caused by NSAIDs co-administered to these patients. Binding to SAPL could also be one of the reasons why gold and aluminium are not taken up in the circulation - which is fortunate in view of their neurotoxic effects when delivered intraveneously. A similar role for bismuth is possible.

Thus the concept of a gastric mucosal barrier of tightly packed hydrocarbon chains provided by surfactant molecules bound to the surface by their polar ends offers a simple physical model for an 'inside lining' based on principles well accepted in the physical sciences, ${ }^{84}$ together with an explanation for the hydrophobic nature of the normal gastric mucosa and many aspects of mucosal protection.

Paediatric Respiratory Research Centre,

B A HILLS

Mater Children's Hospital,

South Brisbane, Queensland, 4101,

Australia
1 Davenport HW, Warner HA, Code CF. Functional significance of gastric mucosal barrier to sodium. Gastroenterology 1964; 47: 142-52.

2 Davenport HW. The gastric mucosal barrier - a swan song. Ann Arbor: University of Michigan,

3 Fromm D. Gastric mucosal barrier. In: Johnson LR, ed. Physiology of the gastrointestinal tract. New York: Raven, 1981: 733-45.

4 Allen A. Gastrointestinal mucus. In: Schultz SG, Forte JG, Rauner BB, eds. Handbook of physiology. Sect 6, vol III. Washington: American Physiological Society, 1989: 359-82.

5 Silen W. New concepts of the gastric mucosal barrier. Am $\mathcal{F}$ Surg 1977; 133: 8-12.

6 Hills BA, Butler BD, Lichtenberger LM. Gastric mucosal barrier: hydrophobic lining to the lumen of the stomach. Am f Physiol 1983; 244 561-8.

7 Spychal RT, Goggin PM, Marrero JM, Saverymuttu SA, Yu CW, Corbishey $\mathrm{CM}$, et al. Surface hydrophobicity of gastric mucosa in peptic ulcer disease: relationship to gastritis and Campylorbacter pylori infection. Gastroenterology 1990; 98: 1250-4.

8 Nathan CC. Corrosion inhibitors. Houston: National Association of Corrosion Engineers. 1972: 71-75.

9 Hills BA. What is the true role of surfactant in the lung? Thorax $1981 ; 36$ : $1-4$.

10 Wassef MK, Lin YN, Horowitz MI. Molecular species of phosphatidylcholine from rat gastric mucosa. Biochim Biophys Acta 1979; 573 $222-6$.

11 Butler BD, Lichtenberger LM, Hills BA. Distribution of surfactants in the canine GI tract and their ability to lubricate. $A m \mathcal{F}$ Physiol: GI and Liver 1983; 7: 742-8.

12 Untersee $P$, Gil J, Weibel ER. Visualization of extracellular lining layer of lung alveoli by freeze-etching. Respir Physiol 1971;13: 171-85.

13 Hills BA. A physical identity for the gastric mucosal barrier. Med $f$ Aust 1990; 153: 76-81.

14 Kao YJ, Goddard PJ, Lichtenberger LM. Morphological effects of aspirin and prostaglandin on the canine gastric mucosal surface. Gastroenterology 1990; 98: 592-606.

15 Goddard PJ, Kao YJ, Lichtenberger LM. Luminal surface hydrophobicity of canine gastric mucosa is dependent on a surface mucous gel. Gastroenterology 1990; 98: 361-70.

16 Ueda S, Kawamura K. Ishii N, Matsumoto S, Hayashi O, Okayasu M, et al. Morphological studies on surface lining layer of the lungs. Part VI. Surfactant-like substance in other organs (pleural cavity, vascular lumen and gastric lumen) than lungs. $\mathcal{F}$ fap Med Soc Biol Interface 1986; 17: and gas.

17 Stratton CJ. Morphology of surfactant producing cells and of the alveolar lining layer. In: Robertson B, Van Golde LMG, eds. Pulmonary surfactant. lining layer. In: Robertson B, Van Golde

18 Slomiany BL, Slomiany A. Glycosphingolipids, glyceroglucolipids of glandular epithelial tissue. In: Sweeley CC, ed. Cell surface glycolipids. Washington: American Chemical Society, 1980: 149-76.

19 Slomiany BL, Sarosiek J, Liau YH, Laszewics W, Slomiany A. Lysolecithin affects the viscosity, permeability and peptic susceptibility of gastric mucin. Scand F Gastroenterol 1986; 21: 1073-9.

20 Slomiany BL, Piasek A, Sarosiek J, Slomiany A. The role of surface and intracellular mucus in gastric mucosal protection against hydrogen ion. Scand $\mathcal{F}$ Gastroenterol 1985; 20: 1191-6.

21 Smith R, Tanford C. The critical micelle concentration of L- $\alpha$-dipalmitoyl phosphatidylcholine in water and water/methanol solutions. 9 Molec Biol 972; 67: 75-83

22 Hills BA. A mucosal barrier of gastric surfactant identified on the human stomach. Aust NZ Med f 1992; 22: 441-4.

23 Hills BA, Kirwood CA. Gastric mucosal barrier: barrier to hydrogen ion imparted by gastric surfactant in vitro. Gut 1992; 33: 1039-41.

24 Williams SE, Turnberg LA. Demonstration of a pH gradient across mucus adherent to rabbit gastric mucosa: evidence for a 'mucus bicarbonate' barrier. Gut 1981; 22: 94-6.

25 Crang RFE, Klomparens KL. Artifacts in biological electron microscopy. New York: Plenum, 1988.

26 Hills BA. Gastric mucosal barrier: evidence for Helicobacter pylori ingesting surfactant and deriving protection from it. Gut 1993; 34: 588-93.

27 Beament JWL. Wax secretion in the cockroach. 7 Exp Biol 1945; 32: 514-38.

28 Hills BA. Gastric mucosal barrier: stabilization of hydrophobic lining to the stomach by mucus. Am F Physiol 1985; 249: 342-9.

29 Tien HT. Bilayer lipid membranes (BLM). Fournal 1974: 46-63.

30 Goddard PJ, Hills BA, Lichtenberger LM. Does aspirin damage canine gastric mucosa by reducing its surface hydrophobicity? Am $\mathcal{F}$ Physiol 1987 252: 421-30.

31 Kiviluoto T, Paimela H, Mustonen H, Kivilaakso E. Exogenous surfaceactive phospholipid protects necturus gastric mucosa against luminal acid and barrier-breaking agents. Gastroenterology 1991; 100: 38-46.

32 Lichtenberger LM, Richards, JE, Hills BA. Effects of prostaglandin PGE on the surface hydrophobicity of aspirin-treated canine gastric mucosa. Gastroenterology 1985; 88: 308-14.

33 Slomiany A, Slomiany BL, Horowitz MI. Studies on changes in lipid profiles of the rat gastric mucosa with stress ulcers. Clin Chim Acta 1975; 59, of the rat

34 Hills BA. The biology of surfactant. Cambridge: Cambridge University Press, 1988

35 Raedsch R, Stiehl A, Pohl S, Plachky J. Quantification of phospholipase $A_{2}$ activity of Campylobacter pylori. Gastroenterology 1989; 96: 478.

36 Ottlecz A, Romero JJ, Hazell SL, Graham DY, Lichtenberger LM Phospholipase activity of Helicobacter pylori and its inhibition by bismuth salts. Dig Dis Sci 1993; 38: 2071-80.

37 Steer HW. Surface morphology of gastroduodenal mucosa in duodena ulceration. Gut 1984; 24: 1203-10.

38 Taha AS, Capell HA, Sturrock RD. Non-steroidal peptic damage in rheumatoid patients receiving second-line drugs. Am $\mathcal{F}$ Gastroenterol 1991; 86: $1588-91$.

39 Hills BA. A hydrophobic oligolamellar lining to surfaces in various tissues: a ubiquitous barrier. Med Sci Res 1992; 20: 543-50.

40 Kellow JE, Tao Z, Piper DW. Ventilatory function in chronic peptic ulcer: a study of ventilatory function in patients with gastric and duodenal ulcer. a study of ventilatory function in part

41 Hills BA. Oligolamellar lubrication of joints by surface-active phospholipid. § Rheumatol 1989; 16: 82-91. 
42 Maher JF. Lubrication of the peritoneum. Perit Dial Int 1992; 12: 346-9.

43 Rainsford KD, Whitehouse MW. Are all aspirins really alike? A comparison of gastric ulcerogenicity with bio-efficacy in rats. Pharmacol Res Commun 1980; 12: 85-95

44 Brandt $\mathrm{KD}$. Should non-steroidal anti-inflammatory drugs be used to treat osteoarthritis? Rheum Dis Clin North Am 199; 19: 29-44.

45 Szelenyi I, Engler H. Cytoprotective role of gastric surfactant in the ethanolproduced gastric mucosal injury of the rat Pharmacology 1986; 33: produced

46 Cerutti P, Kapanci Y. Effect of ambroxol on type II epithelium of the lung. Respiration 1979; 7: 241-51.

47 Leyck S, Dereu N, Etschenberg E, Ghyczy M, Graf E, Winkelmann J, $e t$ al. Improvement of the gastric tolerance of non-steroidal antiet al. Improvement of the gastric tolerance of non-steroidal anti-
inflammatory drugs by polyene phosphatidylcholine (Phospholipon 100). inflammatory drugs by polyene phosph

48 Swarm RA, Ashley SW, Soybel DI, Ordway FS, Cheung LY. Protective effect of exogenous phospholipid on aspirin-induced gastric mucosal effect of exogenous phospholipid

49 Martin GP, Marriott C. Membrane damage by bile salts: the protective function of phospholipids. F Pharm Pharmacol 1981; 31: 754-9.

50 Kivinen A, Tarpila S, Salminen S, Vapaatalo H. Gastroprotection with milk phospholipids: a first human study. Milchwissenschaft 1992; 47: 694-6.
51 Best $R$, Lewis DA, Nasser N. The anti-ulcerogenic activity of the unripe plantain banana (Musa species). Br $\mathcal{F}$ Pharmacol 1984; 82: 107-16.

52 Hills BA, Kirkwood CA. Surfactant approach to the gastric mucosal barrier: protection of rats by banana even when acidified. Gastroenterology 1989; 97: 294-303

53 Hills BA. Novel dairy product. Australian patent 62820, 1992.

54 Hills BA. Effect on gastric surfactant. In: Hollander D, Tytgat GNT, eds. Sulcralfate: from basic science to the bedside. New York: Plenum, 1995:

55 Israelachvili JN. Intermolecular and surface forces. London: Academic Press, 1985: 43.

56 Nagashima R. Development and characteristics of sucralfate. $\mathcal{f}$ Clin Gastroenterol 1981; 3 (suppl 2): 103-10.

57 Watkins JC. The surface properties of pure phospholipids in relation to those of lung extracts. Biochim Biophys Acta 1968; 152: 293-306.

58 Taha AS, Sturrock AD. The gold plated stomach? Ann Rheum Dis 1993; 52: 89-90.

59 Meakins RJ. Alkyl quaternary ammonium compounds as inhibitors of the acid corrosion of steel. F Appl Chem 1963; 13: 339-45.

60 Fancutt F, Hudson JC, Protective painting of structural steel. London: Macmillan, 1957: 28-9. 